\title{
Heterossexismo, falso reconhecimento e capitalismo: uma resposta a Judith Butler ${ }^{1}$
}

Nancy Fraser

O ensaio de Judith Bulter ${ }^{2}$ é bem-vindo sob vários aspectos. Ele nos faz retomar questões profundas e importantes em teoria social, as quais têm permanecido sem discussão por tempo demais. Além disso, ele conecta uma reflexão sobre tais questões a um diagnóstico do estado problemático da esquerda na conjuntura política atual. Mais importante, porém, é o comprometimento de Butler nesse ensaio em identificar e recuperar aspectos genuinamente valiosos do marxismo e do feminismo socialista dos anos 1970, que os atuais modismos políticos e culturais conspiram para reprimir. Igualmente exemplar é seu interesse em integrar os melhores insights de tais paradigmas com vertentes defensáveis de paradigmas mais recentes - incluindo a análise do discurso, os estudos culturais e o pós-estruturalismo - para entender o capitalismo contemporâneo. Esses são compromissos que compartilho de todo o coração.

Não obstante, Butler e eu discordamos. Nossas discordâncias mais importantes - e também as mais frutíferas para discussão - voltam-se para como exatamente realizar este projeto comum de reivindicação e integração. Nós possuímos visões diferentes do que constitui precisamente o legado mais duradouro do marxismo

\footnotetext{
${ }^{1}$ Agradeço os comentários proveitosos de Laura Kipnis, Linda Nicholson e Eli Zaretsky.

2 BUTLER, J. Merely Cultural. Social Text, vol. 15, n. 3-4, p. 265-277, 1997. A tradução do artigo de Butler foi publicada na Parte I do dossiê Diálogos na Teoria Crítica (Revista Idéias, vol. 7, n. 2, p. 229-248, 2016) [N. T.].
} 
e dos insights ainda relevantes do feminismo socialista. Também divergimos em nossas respectivas avaliações sobre os méritos de várias correntes pós-estruturalistas e em nossas respectivas visões de como elas podem informar melhor uma teoria social que preserve uma dimensão materialista. Finalmente, discordamos sobre a natureza do capitalismo contemporâneo.

A fim de abrir o caminho para uma discussão frutífera sobre estes temas, quero começar apontando rapidamente o que considero serem falsas questões. Butler conjuga sua discussão do meu livro, Justice Interruptus, a uma crítica de um grupo de interlocutores anônimos que ela chama de "marxistas neoconservadores". Sejam quais forem os méritos de sua crítica a este grupo - uma questão à qual voltarei mais tarde -, sua estratégia de utilizá-la para circunscrever uma discussão do meu trabalho é infeliz. Apesar de suas afirmações em sentido contrário, os leitores poderiam chegar à conclusão errônea de que compartilho com o "neomarximo conservador" a desqualificação das opressões de gays e lésbicas como "meramente culturais" e, portanto, como secundárias, derivadas ou mesmo triviais. Além disso, eles poderiam presumir que vejo a opressão sexual como menos fundamental, material e real do que a opressão de classe, e que eu gostaria de subordinar as lutas contra o heterossexismo às lutas contra a exploração dos trabalhadores. Vendo-me então agrupada junto a marxistas "ortodoxos sexualmente conservadores", os leitores poderiam até concluir que considero os movimentos gays e lésbicos como particularismos injustificados que dividiram a esquerda e aos quais desejo forçosamente impor uma unidade.

Não acredito, é claro, em nada do tipo. Ao contrário, em Justice Interruptus analisei as atuais dissociações entre a chamada política da identidade e a política de classe, entre a esquerda cultural e a esquerda social, como um traço constitutivo da condição "pós-socialista". ${ }^{3}$ Buscando superar estas divisões

${ }^{3}$ Ver especialmente a Introdução e o Capítulo 1 ("From Redistribution to Recognition? Dilemmas of Justice in a 'Postsocialist' Age") em: FRASER, N. Justice Interruptus: Critical Reflections on the "Postsocialist" Condition. New 
e articular uma base para uma frente unida da esquerda, propus um enquadramento teórico que evita distinções ortodoxas entre "base" e "superestrutura", opressões "primárias" e "secundárias", e que desafia o primado do econômico. Neste processo, teorizei a irredutibilidade conceitual da opressão heterossexista e a legitimidade moral das reivindicações de gays e lésbicas.

Central a este enquadramento é a distinção normativa entre injustiças de distribuição e injustiças de reconhecimento. Longe de revogar as últimas como "meramente culturais", trata-se de conceituar dois danos igualmente primários, sérios e reais, que qualquer ordem social moralmente defensável deve erradicar. Sob meu ponto de vista, ser falsamente reconhecido [misrecognized] não é simplesmente ser menosprezado ou desvalorizado nas atitudes conscientes ou crenças mentais de outros. Trata-se, antes, de ter negado o status de parceiro integral nas interações sociais e de ser impedido de participar como um igual na vida social - não como consequência de uma desigualdade distributiva (como não receber a sua justa parte de recursos ou "bens primários"), senão como consequência de padrões institucionalizados de interpretação e avaliação, que constituem alguém como comparativamente indigno de respeito ou estima. Quando tais padrões de desrespeito e desconsideração são institucionalizados, por exemplo, na lei, nas políticas de bem-estar social, na medicina e/ou na cultura popular, eles impedem a paridade de participação tão certamente como fazem as desigualdades distributivas. Nos dois casos, o dano é bastante real.

$\mathrm{Na}$ minha concepção, portanto, o falso reconhecimento [misrecognition] é uma relação social institucionalizada, não um estado psicológico. Em essência uma injustiça de status, ele é analiticamente distinto e conceitualmente irredutível à injustiça de má distribuição [maldistribution], apesar de poder ser acompanhado por esta última. Se o falso reconhecimento se converte em má distribuição, e vice-versa, isso depende da natureza da formação social em questão. Em sociedades pré-estatais e pré-capitalistas,

York: Routledge, 1997. 
por exemplo, nas quais o status simplesmente é o princípio geral de distribuição e a ordem de status e a hierarquia de classe encontramse, portanto, fundidas, o falso reconhecimento simplesmente acarreta má distribuição. Nas sociedades capitalistas, em contraste, onde a institucionalização de relações econômicas especializadas permite uma relativa separação da distribuição econômica das estruturas de prestígio, e onde status e classe podem, portanto, divergir, falso reconhecimento e má distribuição não são inteira e mutuamente conversíveis. Se, e até que ponto, eles coincidem hoje é uma questão que considerarei adiante.

Normativamente, contudo, o ponto-chave é o seguinte: o falso reconhecimento constitui uma injustiça fundamental, seja acompanhada por má distribuição ou não. E este ponto tem consequências políticas. Não é necessário mostrar que uma dada instância de falso reconhecimento traz com ela má distribuição a fim de certificar a reivindicação de corrigi-la como uma demanda genuína por justiça social. Este ponto é válido para o falso reconhecimento de caráter heterossexista, o qual envolve a institucionalização de interpretações e normas sexuais que negam a paridade de participação a gays e lésbicas. Oponentes do heterossexismo não precisam se esforçar para traduzir reivindicações de danos de status ligados à sexualidade em reivindicações de privação de classe para justificá-las. Tampouco precisam mostrar que suas lutas ameaçam a ordem capitalista para provar que são justas.

Do meu ponto de vista, então, injustiças de falso reconhecimento são exatamente tão sérias quanto injustiças de distribuição. E elas não podem ser reduzidas às últimas. Assim, longe de afirmar que os danos culturais são reflexos superestruturais dos danos econômicos, propus uma análise na qual os dois tipos de danos são igualmente fundamentais e irredutíveis conceitualmente. Sob minha perspectiva, portanto, não faz qualquer sentido dizer que o falso reconhecimento heterossexista é "meramente cultural". Esta locução pressupõe 
a mesma espécie de modelo base-superestrutura, a mesma espécie de monismo economicista que meu enquadramento busca deslocar.

Butler, em suma, confundiu o que é, de fato, um dualismo quase weberiano de status e classe com um monismo economicista marxiano ortodoxo. Ao presumir erroneamente que distinguir a redistribuição do reconhecimento é necessariamente desvalorizar o reconhecimento, ela trata minha distinção normativa como uma "tática" visando depreciar as lutas gays e lésbicas e impor uma nova "ortodoxia". Contra Butler, pretendo defender a distinção e, ao mesmo tempo, negar a tática. Portanto, para chegar às questões reais entre nós, é preciso dissociar duas problemáticas que são identificadas de modo excessivamente próximo em sua discussão. A primeira é uma questão política relativa à profundidade e à seriedade da opressão heterossexista; sobre isso, conforme argumentei, nós não discordamos. A segunda é uma questão teórica que diz respeito ao status conceitual do que Butler erroneamente chama de "distinção material/cultural" na medida em que se relaciona com a análise do heterossexismo e com a natureza da sociedade capitalista; aqui residem nossas discordâncias reais. ${ }^{4}$

${ }^{4}$ No que se segue, deixarei de lado um problema da interpretação de Butler acerca do argumento de Justice Interruptus. Ela me apresenta como argumentando categoricamente que o heterossexismo é uma pura injustiça de falso reconhecimento, sem qualquer ligação com a má distribuição. Na verdade, discuti a questão hipoteticamente na forma de um experimento de pensamento. Buscando revelar a lógica distintiva das reivindicações, respectivamente, de redistribuição e de reconhecimento, convidei os leitores a imaginar um espectro conceitual de coletividades oprimidas, desde vítimas típico-ideais de pura má distribuição de um lado até vítimas típico-ideais de puro falso reconhecimento de outro, com casos híbridos ou "bivalentes" entre eles. Neste espírito hipotético, esbocei uma concepção de "sexualidade desprezada" como uma aproximação concreta do tipo ideal no polo de falso reconhecimento do espectro, notando explicitamente que esta concepção de sexualidade era controvertida e deixando aberta a questão de se, e quão proximamente, ela correspondia às coletividades homossexuais efetivamente existentes em luta por justiça no mundo real. Assim, minha análise do 
Permitam-me começar a examinar estas discordâncias mediante uma recapitulação esquemática da crítica de Butler. De acordo com minha leitura, ela oferece três argumentos teóricos principais contra meu enquadramento de redistribuição/ reconhecimento. Primeiro, ela alega que, porque gays e lésbicas sofrem danos econômicos e materiais, sua opressão não é adequadamente categorizada como falso reconhecimento. Segundo, ao invocar importantes insights do feminismo socialista dos anos 1970 de que a família é parte do modo de produção, ela argumenta que a regulação heteronormativa da sexualidade é "central ao funcionamento da economia política" e que as lutas contemporâneas contra tal regulação "ameaçam a viabilidade" do sistema capitalista. Terceiro, depois de revisitar as narrativas antropológicas das trocas pré-capitalistas, ela sustenta que a

heterossexismo baseada no "falso reconhecimento" em Justice Interruptus é muito mais qualificada do que Butler dá a entender. Além disso, defendi recentemente que, para fins práticos, virtualmente todas as coletividades oprimidas do mundo real são "bivalentes". Ou seja, virtualmente todas elas têm tanto um componente econômico como um de status; virtualmente todas, portanto, sofrem tanto de má distribuição quanto de falso reconhecimento, de maneira que nenhuma dessas injustiças é um mero efeito indireto da outra, mas cada uma tem um peso independente. Não obstante, nem todas elas são bivalentes do mesmo modo ou no mesmo grau. Alguns eixos de opressão tendem mais fortemente em direção ao polo da distribuição do espectro, enquanto outros se inclinam mais para o polo do reconhecimento, e outros ainda se posicionam próximos ao centro. Nesta perspectiva, o heterossexismo, enquanto consistindo em parte de má distribuição, diz respeito primariamente a injustiças de falso reconhecimento e está radicado predominantemente em uma ordem de status que constrói a homossexualidade como desvalorizada e que a institui como uma sexualidade desprezada. $\mathrm{O}$ argumento original encontra-se no capítulo 1 de Justice Interruptus e foi subsequentemente refinado em FRASER, N. Social Justice in the Age of Identity Politics: Redistribution, Recognition, and Participation. In: The Tanner Lectures on Human Values, vol. 18. Salt Lake City: University of Utah Press, no prelo. [O texto foi posteriormente publicado como o primeiro capítulo de FRASER, N.; HONNETH, A. Redistribution or Recognition? A Political-philosophical Exchange. London: Verso Books, 2003, p. 7-109. N. T.]. 
distinção entre o material e o cultural é "instável", um "anacronismo teórico" a ser evitado pela teoria social. Sob meu ponto de vista, nenhum desses argumentos é persuasivo, em grande parte porque nenhum deles oferece uma visão adequadamente diferenciada e historicamente situada da sociedade capitalista moderna. Permitam-me considerar esses três argumentos um por vez.

$\mathrm{O}$ primeiro argumento de Butler apela a alguns fatos incontestáveis sobre os danos sofridos atualmente por gays e lésbicas. Longe de serem "meramente simbólicos", estes danos incluem sérias desvantagens econômicas com inegáveis efeitos materiais. Hoje, nos Estados Unidos, por exemplo, gays e lésbicas podem ser sumariamente dispensados de cargos civis e do serviço militar, ter negada uma ampla variedade de benefícios sociais baseados na família, ser desproporcionalmente sobrecarregados com custos médicos, além de estarem em desvantagem nas leis de impostos e herança. Igualmente materiais são os efeitos do fato de homossexuais não disporem de uma vasta gama de proteções e direitos constitucionais usufruídos por heterossexuais. Em muitas jurisdições, eles podem ser processados por sexo consensual; e em muitos outros, podem ser agredidos com impunidade. Butler defende que o caráter material e econômico destes prejuízos faz com que a análise do heterossexismo baseada no "falso reconhecimento" esteja equivocada.

A premissa de Butler de fato é verdadeira, mas sua conclusão não se segue. Ela presume que injustiças de falso reconhecimento devam ser imateriais e não econômicas. Deixando de lado, por ora, sua conjunção do material com o econômico, sua suposição erra nos dois aspectos. Na minha concepção, injustiças de falso reconhecimento são tão materiais quanto injustiças de má distribuição. É claro que as primeiras estão radicadas em padrões sociais de interpretação, avaliação e comunicação, portanto, se se quiser, na ordem simbólica. Mas isso não quer dizer que eles são "meramente" simbólicos. Ao contrário, as normas, significados e construções da condição de pessoa [constructions of personhood] que impedem mulheres, pessoas racializadas e/ou gays e lésbicas 
de exercerem a paridade de participação na vida social são materialmente instanciadas - em instituições e práticas sociais, na ação social e no habitus corporificado, e sim, também em aparelhos ideológicos de Estado. Longe de ocupar um reino diáfano e etéreo, elas são materiais, tanto em sua existência quanto em seus efeitos.

Sob minha perspectiva, portanto, os danos materiais citados por Butler constituem casos paradigmáticos de falso reconhecimento. Eles refletem a institucionalização de significados, normas e construções heterossexistas da condição de pessoa em arenas tais como a lei constitucional, a medicina, as políticas de imigração e naturalização, os códigos de impostos estaduais e federais, as políticas de emprego e bem-estar social, a legislação de oportunidades iguais, e assim por diante. Ademais, o que é institucionalizado, conforme a própria Butler nota, são as construções culturais de direitos e da condição de pessoa que produzem os sujeitos homossexuais como abjetos. Esta, para dizer de novo, é a essência do falso reconhecimento: a construção material, por meio da institucionalização de normas culturais, de uma classe de pessoas desvalorizadas que são privadas da paridade participativa.

Deste modo, se os danos que resultam do falso reconhecimento podem ser materiais, eles podem também ser econômicos? É verdade, como Butler nota, e como eu mesma notei expressamente em Justice Interruptus, que algumas formas de heterossexismo infligem danos materiais em gays e lésbicas. Aquestãoécomointerpretá-los. ${ }^{5}$ Uma possibilidadeéverestes danos econômicos como expressões diretas da estrutura econômica da sociedade - em grande parte como os marxistas veem a exploração dos trabalhadores. Segundo esta interpretação, que Butler parece endossar, os prejuízos econômicos de homossexuais estariam profundamente arraigados nas relações de produção. Remediá-

\footnotetext{
${ }^{5}$ Em geral, devem-se distinguir diversas questões aqui: 1) a natureza das injustiças em questão; 2) suas causas últimas; 3) os mecanismos causais contemporâneos que as reproduzem; e 4) seus remédios. Sou grata a Erik Olin Wright por este ponto (comunicação privada, 1997).
} 
los requereria transformar essas relações. Outra possibilidade, preferida por mim, é ver os danos econômicos do heterossexismo como consequências distributivas indiretas da injustiça mais fundamental de falso reconhecimento. Nesta interpretação, que propus em Justice Interruptus, as raízes do heterossexismo econômico seriam as "relações de reconhecimento": um padrão institucionalizado de interpretação e valorização que concebe a heterossexualidade como normativa e a homossexualidade como desviante, negando deste modo a paridade participativa a gays e lésbicas. Mudando as relações de reconhecimento, a má distribuição despareceria.

Este conflito de interpretações levanta questões profundas e difíceis. É necessário transformar a estrutura econômica do capitalismo contemporâneo para poder corrigir as desvantagens econômicas dos homossexuais? O que precisamente significa "estrutura econômica"? Deve-se considerar a regulação heteronormativa da sexualidade como pertencendo diretamente à economia capitalista? Ou ela é mais bem compreendida como pertencendo a uma ordem de status que é diferenciada da, e complexamente relacionada com, a estrutura econômica? De maneira mais geral, as relações de reconhecimento nas sociedades tardo-capitalistas coincidem com as relações econômicas? Ou as diferenciações institucionais do capitalismo moderno introduzem lacunas entre status e classe?

Para prosseguir com estas questões, permitam-me examinar o segundo argumento de Butler. Aqui ela invoca o insight do feminismo socialista dos anos 1970 de que a família é parte do modo de produção, a fim de sustentar a tese de que a regulação heteronormativa da sexualidade é "central ao funcionamento da economia política". Disso resulta, Butler afirma, que as lutas contemporâneas contra aquela regulação "ameaçam a viabilidade" do sistema capitalista.

Na verdade, duas variações diferentes do argumento podem ser discernidas aqui, uma definicional, outra funcionalista. De acordo com a primeira versão, a regulação (hetero)sexual pertence por definição à estrutura econômica. A estrutura econômica 
simplesmente é todo o conjunto de mecanismos e instituições sociais que (re)produzem pessoas e bens. Por definição, assim, a família é parte desta estrutura, sendo o local primário da reprodução de pessoas. Também o é, por extensão, a ordem de gênero, a qual padroniza os "produtos" da família para que se adaptem a um entre dois - e somente dois - tipos de pessoas mutuamente excludentes, aparentemente naturais: homem e mulher. A ordem de gênero, por sua vez, é tida como pressupondo um modo de regulação sexual que produz e naturaliza a heterossexualidade, enquanto simultaneamente produz a homossexualidade como abjeta. A conclusão a que chega Butler é que a regulação heteronormativa da sexualidade é uma parte da estrutura econômica por definição, a despeito de não estruturar nem a divisão social do trabalho, nem o modo de exploração da força de trabalho na sociedade capitalista.

Este argumento definicional tem um ar de indiferença olímpica em relação à história. Como resultado, ele corre o risco de realizar coisas demais. Estipular que o modo de regulação sexual pertence à estrutura econômica por definição - mesmo na ausência de qualquer impacto discernível na divisão do trabalho ou no modo de exploração - ameaça des-historicizar a ideia da estrutura econômica e drenar sua força conceitual. $\mathrm{O}$ que se perde é a especificidade da sociedade capitalista como uma forma distintiva e altamente peculiar de organização social. Esta organização cria uma ordem de relações econômicas especializadas que são relativamente dissociadas das relações de parentesco e autoridade política. Assim, na sociedade capitalista, a ligação entre o modo de regulação sexual, de um lado, e a ordem de relações econômicas especializadas, cuja raison d'être é a acumulação de mais-valia, de outro, é atenuada. Ela é certamente muito mais tênue que nas sociedades pré-capitalistas e préestatais, onde as relações econômicas são em grande medida esboçadas por meio dos mecanismos de parentesco e diretamente imbricadas com a sexualidade. Na sociedade tardo-capitalista do século XX, ademais, os vínculos entre sexualidade e acumulação de mais-valia foram ainda mais atenuadas pela ascensão daquilo que Eli Zaretsky chamou de "vida pessoal": um espaço de relações 
íntimas, incluindo sexualidade, amizade e amor, que não pode mais ser identificado com a família e que é vivido como desconectado dos imperativos de produção e reprodução. ${ }^{6}$ Em geral, então, a sociedade capitalista contemporânea contém "lacunas": entre a ordem econômica e a ordem de parentesco; entre a família e a vida pessoal; e entre a ordem de status e a hierarquia de classe. Neste tipo de sociedade altamente diferenciada, não faz qualquer sentido para mim conceber o modo de regulação sexual como simplesmente uma parte da estrutura econômica. Nem em conceber as reivindicações queer por reconhecimento da diferença como demandas deslocadas por redistribuição.

Em outro sentido, além disso, o argumento definicional realiza coisas de menos. Butler quer concluir que as lutas acerca da sexualidade são econômicas, mas esta conclusão foi tornada tautológica. Se as lutas sexuais são econômicas por definição, então elas não são econômicas no mesmo sentido das lutas contra os índices de exploração. Simplesmente chamando os dois tipos de lutas "econômicas", arrisca-se a fazer as diferenças entrarem em colapso, criando a impressão equivocada de que elas vão entrar em sinergia automaticamente e embotando nossa capacidade de colocar, e de responder, questões políticas difíceis mas prementes sobre como fazê-las entrarem em sinergia quando, de fato, elas divergem ou estão em conflito. ${ }^{7}$

${ }^{6}$ ZARETSKY, E. Capitalism, the Family, and Personal Life. New York: Harper \& Row, 1976.

${ }^{7}$ Assim, o argumento definicional simplesmente empurra a necessidade de distinções para outro nível. Com certeza, pode-se dizer que uma reivindicação política pode ser econômica em qualquer dos dois sentidos: primeiro, contestando a produção e a distribuição de valor econômico, inclusive a mais-valia; e segundo, contestando a produção e a reprodução de normas, significações e construções do estatuto da pessoa, inclusive aquelas concernentes à sexualidade. Mas não consigo ver como isso melhora minha estratégia mais simples de restringir o termo econômico a seu significado capitalista e de distinguir as reivindicações por reconhecimento das reivindicações por redistribuição. 
Isso me leva à variação funcionalista do segundo argumento de Butler. Aqui, a alegação é que a regulação heteronormativa da sexualidade é econômica - não por definição, mas porque é funcional para a expansão da mais-valia. Em outras palavras, o capitalismo "precisa" ou se beneficia da heterossexualidade compulsória. Segue-se, de acordo com Butler, que as lutas gays e lésbicas contra o heterossexismo ameaçam a "viabilidade" do sistema capitalista.

Como todos os argumentos funcionalistas, este se sustenta ou é derrubado com as relações empíricas de causa e efeito. Empiricamente, no entanto, é altamente implausível que as lutas de gays e lésbicas ameacem o capitalismo em sua forma histórica realmente existente. Este poderia ser o caso se os homossexuais fossem concebidos como uma classe inferior, porém útil, de trabalhadores servis cuja exploração fosse central para o funcionamento da economia, como foram os afro-americanos, por exemplo. Assim, poder-se-ia dizer que os interesses do capital são favorecidos ao mantê-los "no seu lugar". Na realidade, porém, os homossexuais são mais frequentemente concebidos como um grupo cuja própria existência é uma abominação, num certo sentido como a concepção nazista dos judeus; eles não deviam ter qualquer "lugar" na sociedade. Não é, pois, de surpreender que os principais oponentes dos direitos de gays e lésbicas hoje sejam não as corporações multinacionais, mas sim os conservadores religiosos e culturais, cuja obsessão é o status, não o lucro. De fato, algumas multinacionais - notadamente a American Airlines, a Apple Computers e a Disney - despertaram a ira de tais conservadores ao instituir políticas favoráveis aos gays, tais como benefícios de parceria doméstica. Elas aparentemente veem vantagens em acomodar gays, desde que não sejam sujeitas a boicotes ou, alternativamente, que sejam grandes o suficiente para resistir a eles caso isso aconteça.

Empiricamente, portanto, o capitalismo contemporâneo parece não exigir o heterossexismo. Com suas lacunas entre a ordem econômica e a ordem de parentesco, e entre a família e a vida pessoal, a sociedade capitalista agora permite que um número 
significativo de indivíduos viva de seu trabalho assalariado fora de famílias heterossexuais. Isso seria permitido a muitos mais desde que as relações de reconhecimento fossem alteradas. Assim, podemos agora responder a uma questão colocada anteriormente: as desvantagens econômicas dos homossexuais são mais bem compreendidas como efeitos do heterossexismo nas relações de reconhecimento do que como profundamente arraigadas na estrutura do capitalismo. A boa notícia é que não precisamos derrubar o capitalismo a fim de remediar estas desvantagens - apesar de podermos muito bem precisar derrubá-lo por outras razões. A má notícia é que precisamos transformar a ordem de status existente e reestruturar as relações de reconhecimento.

Com seu argumento funcionalista, Butler ressuscitou o que é, sob meu ponto de vista, um dos piores aspectos do marxismo e do feminismo socialista dos anos 1970: a visão totalizadora da sociedade capitalista como um "sistema" monolítico de estruturas entrelaçadas de opressão que se reforçam umas às outras sem quebras. Esta perspectiva não considera as "lacunas". Isso têm sido reiterada e persuasivamente criticado a partir de muitas direções, incluindo o paradigma pós-estruturalista que Butler endossa e o paradigma weberiano por mim adaptado. A teoria funcionalista dos sistemas é uma vertente do pensamento dos anos 1970 que é melhor esquecer.

A questão sobre o que deveria substituir o funcionalismo diz respeito ao terceiro argumento de Butler contra meu recorte redistribuição/reconhecimento. Este argumento é desconstrutivo. Longe de insistir que as raízes do heterossexismo são econômicas em oposição ao "meramente cultural", sua intenção é desconstruir a "distinção material/cultural". Esta distinção, afirma Butler, é "instável". Importantes correntes do pensamento neo-marxiano, de Raymond Williams a Althusser, colocaram-na irreversivelmente em "crise". O argumento fulminante provém, no entanto, dos antropólogos, notadamente Mauss e Lévi-Strauss. Suas respectivas considerações da "dádiva" e da "troca de mulheres" revelam que os processos "primitivos" de intercâmbio não podem ser atribuídos a um lado ou a outro da divisão material/cultural. Sendo ambos 
um só processo, eles "desestabilizam" a própria distinção. Logo, ao evocar a separação material/cultural hoje, argumenta Butler, eu teria sucumbido a um "anacronismo teórico".

Este argumento é pouco convincente por vários motivos, o primeiro dos quais é que mistura "o econômico" com "o material". Butler presume que minha distinção normativa entre redistribuição e reconhecimento reside em uma distinção ontológica entre o material e o cultural. Ela presume, assim, que desconstruir a segunda distinção implica puxar o tapete da primeira. Na verdade, entretanto, a suposição não se sustenta. Conforme notei anteriormente, injustiças de falso reconhecimento são, sob minha perspectiva, tão materiais quanto injustiças de má distribuição. Deste modo, minha distinção normativa não se apoia em nenhum fundamento de diferença ontológica. Aquilo com o que ela sim se correlaciona, nas sociedades capitalistas, é a distinção entre o econômico e o cultural. Esta, entretanto, não é uma distinção ontológica, mas uma distinção de teoria social. A distinção econômico/cultural, e não a distinção material/cultural, é o real pomo da discórdia entre nós, a distinção cujo status está em jogo.

Qual, então, é o status conceitual da distinção econômico/ cultural? Os argumentos antropológicos realmente lançam uma luz sobre o assunto, segundo meu ponto de vista, mas não de modo a apoiar a posição de Butler. De acordo com a minha leitura, tanto Mauss quanto Lévi-Strauss analisam processos de trocas em sociedades pré-capitalistas e pré-estatais nas quais o idioma hegemônico das relações sociais era o parentesco. Em suas narrativas, o parentesco organizava não apenas o casamento e as relações sexuais, mas também o processo de trabalho e a distribuição dos bens; as relações de autoridade, reciprocidade e obrigação; e as hierarquias simbólicas de status e prestígio. Não existiam relações distintivamente econômicas ou distintivamente culturais; logo, a distinção econômico/cultural presumivelmente não estava disponível aos membros daquelas sociedades. Disso não se segue, contudo, que a distinção seja sem sentido ou inútil. Pelo contrário, ela pode ser significativa e proveitosamente aplicada às sociedades 
capitalistas, as quais diferentemente das sociedades chamadas "primitivas" contêm, de fato, as diferenciações em questão. ${ }^{8}$ Além disso, ela pode ser aplicada por nós a sociedades que carecem destas diferenciações, de modo a indicar como elas diferem da nossa. Pode-se dizer, por exemplo, como acabei de fazer, que em tais sociedades uma única ordem de relações sociais dá conta de ambas as integrações, a econômica e a cultural, questões que são relativamente dissociadas na sociedade capitalista. Ademais, este é precisamente o espírito no qual entendo Mauss e Lévi-Strauss. Seja qual for sua intenção em relação ao "econômico" e ao "cultural", ganhamos menos ao lê-los como tendo "desestabilizado" a distinção do que como tendo historicizado-a. Em outras palavras, o ponto é historicizar uma distinção central ao capitalismo moderno - e, com ela, o próprio capitalismo moderno -, situando ambos em um contexto antropológico mais amplo e assim revelando sua especificidade histórica.

Deste modo, o argumento de "desestabilização" de Butler perde-se em dois pontos cruciais. Primeiro, ele estende ilegitimamente a sociedades capitalistas um traço específico de sociedades pré-capitalistas: a saber, a ausência de uma diferenciação econômico/cultural. Segundo, ele presume erroneamente que historicizar uma distinção é torná-la insignificante e inútil em teoria social. Na verdade, a historicização faz o contrário. Longe de tornar as distinções instáveis, ela permite que sua utilização seja mais precisa.

${ }^{8}$ Neste breve ensaio, não posso abordar a importante, porém difícil questão de como a distinção econômico/cultural pode ser mais bem aplicada à teoria crítica da sociedade capitalista contemporânea. No entanto, discuto este assunto em profundidade em "Social Justice in the Age of Identity Politics". Rejeitando a visão da economia e da cultura como esferas separadas, proponho uma abordagem crítica que revela as conexões ocultas entre elas. Em outras palavras, trata-se de usar a distinção a contrapelo, tornando visíveis e sujeitos a críticas tanto os subtextos culturais de processos aparentemente econômicos, quanto os subtextos econômicos de processos aparentemente culturais. Tal "dualismo perspectivista" só é possível, é claro, uma vez que tenhamos a distinção econômico/cultural. 
Da minha perspectiva, portanto, a historicização representa uma abordagem melhor da teoria social do que a desestabilização ou a desconstrução. ${ }^{9}$ Ela nos permite avaliar o caráter sócio-estruturalmente diferenciado e historicamente específico da sociedade capitalista contemporânea. Ao fazer isso, ela ainda nos permite localizar o momento antifuncionalista, bem como possibilidades de "agência" contrassistêmica e transformação social. Estas aparecem não em uma propriedade abstrata e trans-histórica da linguagem, como "ressignificação" ou "performatividade", senão no efetivo caráter contraditório de relações sociais específicas. Com um olhar historicamente específico e diferenciado da sociedade capitalista contemporânea, podemos localizar as lacunas, o não isomorfismo de status e classe, as múltiplas interpelações contraditórias de sujeitos sociais e os muitos imperativos morais complexos que motivam as lutas por justiça social.

A partir deste tipo de perspectiva, ademais, a atual conjuntura política não é adequadamente apreendida por um diagnóstico centrado na suposta ressurgência do marxismo ortodoxo. Ela é mais bem compreendida, em vez disso, por um diagnóstico que reconheça francamente e busque superar divisões na esquerda entre correntes socialistas/social-democratas orientadas pelas políticas de redistribuição, de um lado, e correntes multiculturalistas orientadas pelas políticas de reconhecimento, de outro. O ponto de partida indispensável para tal análise deve ser um reconhecimento de princípio de que os dois lados têm reivindicações legítimas, as quais

9 Em um outro nível, contudo, pretendo endossar a desconstrução. Ela representa uma abordagem da política do reconhecimento que é geralmente superior, sob o meu ponto de vista, à política de identidade padrão. Uma política de reconhecimento desconstrutiva é transformativa, não-afirmativa, de identidades e diferenciações de grupos existentes. A este respeito, ela tem afinidades com o socialismo, o qual entendo como uma abordagem transformativa, ao contrário de afirmativa, da política de redistribuição. (Para uma elaboração desse argumento, ver o capítulo 1 de Justice Interruptus) Apesar disso, não considero a desconstrução útil no nível que Butler invoca aqui: nomeadamente, o da teoria social. 
devem ser de algum modo programaticamente harmonizadas e politicamente tornadas sinérgicas. Em suma, justiça social hoje requer ambos, redistribuição $e$ reconhecimento; nenhum deles sozinho será suficiente.

Sobre este último ponto, estou certa, Butler e eu concordamos. A despeito de sua relutância em invocar a linguagem da justiça social, e apesar de nossas divergências teóricas, nós duas estamos comprometidas em recuperar os melhores elementos da política socialista e em integrá-los com os melhores elementos da política dos "novos movimentos sociais". Do mesmo modo, nós duas estamos empenhadas em reabilitar as vertentes genuinamente valiosas da crítica neomarxiana do capitalismo e em integrá-las com as vertentes mais perspicazes da teoria crítica pós-marxiana. O mérito do artigo de Butler, e espero que o do meu próprio livro também, é ter colocado este projeto novamente em pauta.

Tradução: Aléxia Bretas

Publicação original: FRASER, N. Heterosexism, Misrecognition, and Capitalism: A Response to Judith Butler. Social Text, vol. 15, n. 3-4, p. 279-289, 1997. Agradecemos à Duke University Press pela permissão de publicar a tradução deste ensaio. 
